\title{
Exploring relationships between reading attitudes, reading ability and academic performance amongst primary teacher trainees in Swaziland
}

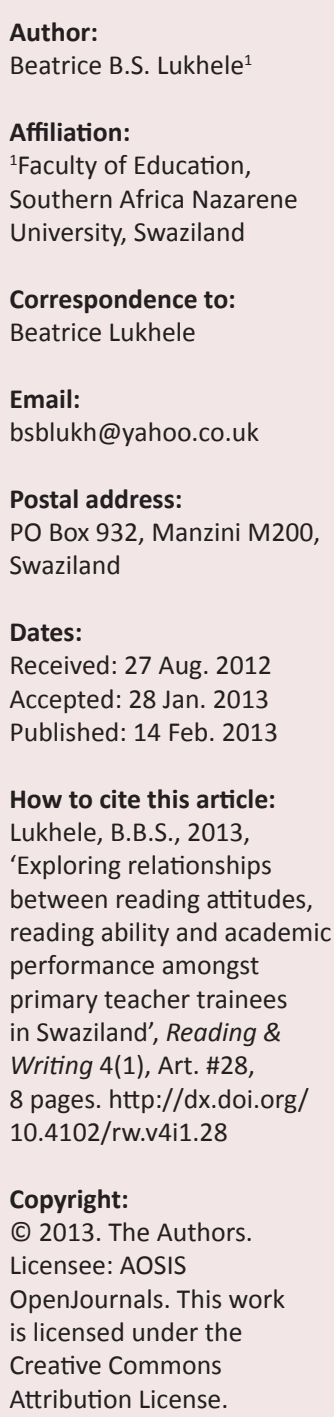

\section{Author}

Beatrice B.S. Lukhele University, Swaziland

\section{Correspondence to:}

\section{Email:}

Postal address:

PO Box 932, Manzini M200,

Swaziland

Dates:

Accepted: 28 Jan. 2013

Published: 14 Feb. 2013

How to cite this article: Lukhele, B.B.S., 2013,

'Exploring relationships performance amongst primary teacher trainees 8 pages. http://dx.doi.org/

Copyright:

Licensee: AOSIS

OpenJournals. This work

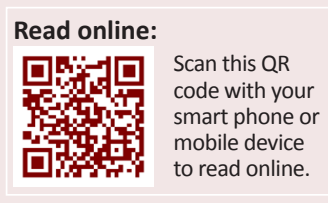

In this research study, relationships between attitudes to reading, reading ability, vocabulary and academic performance were investigated. The data were gathered and triangulated from an attitude questionnaire, an author and magazine recognition test, as well as from reading comprehension and academic test performance of 84 first- and third-year students studying for a Primary Teacher's Diploma at a College in Manzini, Swaziland. The results suggest that whilst there is no relationship between reading attitudes and reading ability, there is some relationship between reading ability and academic performance. The statistical analyses further indicate a relationship between reading and vocabulary ability of the participants. The findings have grave implications regarding attitudes to reading, reading ability and academic performance for a professional cadre that is expected to be influential in the academic lives of impressionable primary school children in an English as Second Language (ESL) context.

\section{Introduction}

Attitudes to reading for leisure were examined in a Swazi context featuring teacher trainees enrolled for the Primary Teacher's Diploma at a Teacher Training College in Manzini, Swaziland. The basis for the study was that the affective domain - attitudes, motivations, interests and personal evaluations on any phenomenon - seems to be influential in the behaviour and practice of Additional Language (AL) learners, as research suggests. The concept of attitudes to reading is defined by McKenna, Kear and Ellsworth (1995:937) as: 'the beliefs that an individual harbors in relation to the object, the behavioral intentions that concern the object, and the feelings the individual experiences because of the object'. These authors argue that it is vital to recognise the important position of 'attitude' when we seek to cultivate readers.

The study involved not only the examination of reading attitudes, but also compared these attitudes to the students' reading ability, vocabulary knowledge and academic performance.

\section{Theoretical framework}

Reading attitudes seem to emanate from perceptions acquired from people's reading history and experience (Guthrie \& Greaney 1991). Day and Bamford (1998) argue that a learner's experience of reading in the first language influences the learner's attitude to reading in the AL. Furthermore, it seems that cultural beliefs are another cradle for the incubation of negative or positive attitudes towards reading (McKenna et al. 1995). A culture where reading is viewed in a negative light by people whose approval a learner seeks, may not encourage positive reading attitudes. This argument underscores the role of teachers, parents and communities in the development of positive reading attitudes. Parents, teachers and communities play a significant role in the mentoring and modelling of the culture of reading, as each group serves as a vital part in the multilateral nature of influence on a child (McKenna 2001).

In the same vein, Mathewson (2004), in his model of reading attitudes, asserts that a positive reading attitude does not guarantee actual reading behaviour. He suggests an additional element: the intention to read/continue reading. He argues that measuring whether attitudes are positive or negative is of little consequence: one's attitude may be positive but one may lack the intention to read, resulting in non-reading behaviour being exhibited.

Mathewson's model of reading attitudes features external motivators and internal states as components that influence one's intention to read/continue reading. External motivators, comprising 'incentives, purpose, norms, and settings outside of readers', form part of the model and, like internal emotional states, they work on one's intention to read and/or continue reading, with reading behaviour as an outcome. Without this aspect, extensive reading remains wishful 
thinking for the individual. Mathewson's reading attitude model brings in 'prevailing feelings about reading, action readiness for reading and evaluative beliefs about reading' as component factors in the reading attitudes (1994:1435). Emotional states and external motivators also influence one's intention to read. This model brings about some balance in one's understanding, in the exploration of reading attitudes.

It is argued that attitudes to reading are set early in the life of an individual, but they are not permanent, whether they are essentially positive or negative (McKenna et al. 1995). It is further suggested that reading attitudes seem to be more positive in the lower grades than in the higher grades (McKenna et al. 1995). An increase in reading seems to improve not only a reader's reading ability but also a reader's attitude to reading. Furthermore, it is suggested that attitudes are a 'stable construct' among children, emphasising the importance of developing positive reading attitudes early in the life of a child (Smith 1990). Research further suggests that reading attitudes are affected by such factors as socio-economic status, home environment, availability of spare time, amount of television watched, quality of kindergarten instruction, library facilities and availability of reading resources at home (Walberg \& Tsai 1995).

It appears that, in some cases, the more years some students spend studying in English as an AL, the less inclination they have to read in English during their leisure hours, due to the lack of interest in reading extensively (Camiciottoli 2001). In contrast, it seems that the more students read in the first language (L1), the more enthusiastic they are to find and read books in the AL (English). It seems that there is a positive correlation between reading attitude and reading in the first language, underscoring the view that the students' success in reading in $\mathrm{L} 1$ influences their AL reading attitude. The challenge apparently faced by students in developing countries is the lack of reading resources in both the first and additional languages. That being said, Roy-Campbell and Qorro's (1997) study in Tanzania underscores the positive self-perceptions of learners' reading attitudes in spite of this lack of access to reading resources in Africa.

However, enquiry into the reading attitudes of tertiary students reveals that extended failure in reading may lead to students' reluctance to make any attempt at using new reading strategies (Pretorius 2005). In her study, Pretorius observes that, because reading is so effortful, students may be reluctant to invest even more effort by applying new strategies. Clearly, students' attitudes to reading may be transformed by the experience of sustained success at reading, with the concomitant consequence of increasing the participants' confidence levels.

Reading ability further seems to provide for the extension and increase of vocabulary. Research suggests that the more a student reads for leisure purposes, the more vocabulary the student acquires (Feitelson et al. 1993; Lao \& Krashen 2000; Min 2008; Roberts 2008). The amount of reading a learner does not only improves reading proficiency but also assists in vocabulary mastery.
Research further suggests that reading extensively not only has a positive effect on reading ability but also a positive effect on academic performance, as argued by Collier (1989). She refers to academic discourse as 'school language' which can be acquired through exposure to different texts. Knowledge of text-types, technical vocabulary, and mapping out relationships between textual elements are necessary skills in text comprehension (Just \& Carpenter 1987), and can be attained through the actual reading of texts.

Increasingly, research seems to suggest that good readers (in general) perform better than non-readers academically. Elley (1991) observed that primary school learners who accessed and read more leisure resources not only did well in reading ability tests but also showed a remarkable improvement in their academic work. It appears that an explanation of this improvement lies in Corson's (1997) argument that science and mathematics discourse has its roots in Graeco-Latin languages. Vocabulary that emanates from the Graeco-Latin background has low-frequency words that a learner can best acquire through exposure to texts that make use of such vocabulary. African learners are at a disadvantage in this regard as African languages do not share the Graeco-Latin base. This kind of exposure seems to be facilitated by reading for pleasure and by exposure to expository texts.

In light of Corson's argument, Pretorius's (2002) study of Grade 4 learners suggests that there seems to be a significant positive correlation between reading ability and academic performance. Further research on this link provides more support for the claim that reading ability correlates significantly with academic performance (Pretorius 2002; Pretorius \& Bohlmann 2003).

That there is not much material for leisure reading in the siSwati mother tongue is a cause for concern. Attempts at introducing a siSwati newspaper have been rendered ineffective because the paper does not get sufficient readership. Nevertheless, students who, despite the odds, have developed a love for books, read all the available siSwati texts that are not prescribed for their class and/or level.

The main challenge in this regard seems to be that many young Swazi people and their parents tend to undermine the importance of siSwati since they believe that it offers no future job opportunities as compared with those offered by a mastery of English. This negative attitude toward siSwati has resulted in very little leisure reading being done in L1. However, good readers generally read anything they can find and so they will read whatever is available in the L1 (Grabe 1991:388). Still, it seems that teachers in primary and high schools need to play a more proactive role in influencing young people to love books and leisure reading.

On the whole, at the lower primary level in schools, some learners struggle to learn to read, to identify and recognise words and make sense out of them, a common occurrence as Stanovich (1991:418) observes. By the third grade, learners embark on a more complex task that should take them 
through their academic career: reading in order to learn (Heath 1991:5). Up to that point, teachers concentrate mainly on getting their learners to master the decoding of a text and read fluently. In the higher grades, children need to develop automaticity in their decoding skills in order to simultaneously to engage the higher order skills of processing the meaning of a text (Grabe 1991:380). Unfortunately, this is when most teachers in this country no longer stress the importance of reading in all the disciplines. This, in turn, creates serious reading difficulties and exacerbates the learners' poor inclination towards reading, thereby precluding the inculcation of a reading culture in the land.

As already pointed out earlier, however, most schools, even some of those in urban areas, do not have any reading material that can help foster a love of reading at the primary school level. In most schools, class readers are a luxury only afforded by the well-to-do. Unless books are donated by publishing houses in the country, few school principals make books a priority in their yearly budget of school finances. Secondary schools are no better off. Very few school administrators are enlightened about the role that books and/or class readers can play in the development of proficiency in the AL and success in learners' academic performance. Their argument is that they were able to learn English without reading books; they generally do not understand what has changed in the learning and teaching of English. And so they insist that teachers of English just have to make sure that learners master and pass the AL.

Clearly, there seems to be no urgency regarding the cultivation of a culture of reading in this country. Reading for leisure purposes is restricted attitudinally and by lack of leisure reading resources. Provision of reading resources normally follows a grave conviction regarding the outcomes of such an exercise. In this country, Swaziland, reading has to be viewed as an activity that must be sown, nurtured, carefully tended and encouraged in order for it to become part of the culture of the land.

No research has been carried out in this country on attitudes toward reading held by teachers in general and student teachers in particular. The purpose of this study was to find out whether teacher trainees held positive or negative attitudes toward reading, and whether these were linked to their reading ability, vocabulary levels and academic performance.

\section{Research questions}

There were four research questions:

1. What are the participants' attitudes to and perceptions of extensive reading?

2. Is there a relationship between the students' reading attitudes and their AL reading ability?

3. Is there a relationship between the students' vocabulary knowledge and their AL reading ability?

4. Is there a relationship between the students' academic performance and their AL reading ability?

\section{Background to the study}

The rationale of the study was based on the fact that the teacher trainees would, on completion of their diploma, leave for schools in the country to be influential in the lives of impressionable young Swazi learners. In light of this momentous task, a crucial question was: what kind of influence would the new teachers wield in terms of attitudes to leisure reading? What are their attitudes toward extensive reading? Do these attitudes affect their reading ability? How does their reading ability affect their academic performance?

This study was undertaken against the backdrop of a country grappling with a myriad challenges, such as the looming insolvency of the state and the scourge of HIV. Problems such as the lack of leisure reading materials seem to be insignificant in light of these socio-economic challenges, yet the worst collapse the country can experience is of an academic nature. This is a context in which reading resources are inadequate, if not non-existent; in most primary and secondary schools, and very little reading is ever done. There are very few books written in both the siSwati and English languages and this is the prevailing state of affairs. The literature that is produced as siSwati novels and short stories is used as prescribed texts for secondary and tertiary siSwati literature courses.

\section{The participants}

Eighty-four students in the College were asked to be part of the study. Thirty-nine were in the third and final year, and 45 in the first year of study, all working towards attaining the Primary Teacher's Diploma (PTD). The PTD firstyear students $(N=45)$ were aged between 18 and 41 . The third-year students $(N=39)$ were in their final year at college and their ages ranged between 18 and 35 . The students were assured that their identities would not be disclosed in the research study and that their privacy would be protected.

The University of Swaziland (UNISWA) which is the certifying and accrediting body for all the academic colleges in the country (including the Training College) requires that, on entry for the PTD, students should hold credit passes in at least four subjects, such as Geography, History, Religious Education, Home Economics, Agriculture, Biology, Science, Mathematics and the siSwati language, as these are core subjects in primary school education. On enrolment, the students do all these subjects and other non-core but compulsory courses such as Art and Craft, Chalkboard writing, Physical Education, Teaching Aids, Music and Academic Communication Skills, all aimed at enhancing teaching professionalism amongst the trainees.

\section{Data collection instruments and analysis}

The researcher used a 41-item questionnaire exploring the attitudes of the teacher trainees regarding leisure reading. This instrument was designed in light of McKenna's (2001) model in which he focuses on three principles: the first being 'the direct impact of episodes of reading' (italics mine); the second relating to one's 'beliefs about the outcomes of 
TABLE 1: Attitudes toward and perceptions of extensive reading.

\begin{tabular}{llllll}
\hline Variables & PTD 1 Mean $(N=45)$ & PTD 1 SD* & PTD 3 Mean $(N=39)$ & PTD 3 SD & Overall Mean $(N=84)$ \\
\hline Attitudes \& perceptions & $71.9 \%$ & 9.79 & $71.9 \%$ & 8.75 & $71.9 \%$ \\
\hline
\end{tabular}

Source: Data compiled by author for article

Values are given as means.

PTD, Primary Teacher's Diploma; SD, Standard Deviation.

TABLE 2: Some questionnaire responses.

\begin{tabular}{|c|c|c|c|}
\hline Questionnaire & $\begin{array}{l}\text { PTD } 1 \\
(N=45)\end{array}$ & $\begin{array}{l}\text { PTD } 3 \\
(N=39)\end{array}$ & $\begin{array}{l}\text { Overall } \\
(N=84)\end{array}$ \\
\hline \multicolumn{4}{|c|}{ 4.Do you enjoy reading? } \\
\hline Not at all & $4 \%$ & $0 \%$ & $2 \%$ \\
\hline A little & $33 \%$ & $36 \%$ & $34.5 \%$ \\
\hline Quite a lot & $49 \%$ & $26 \%$ & $38 \%$ \\
\hline Very much & $14 \%$ & $38 \%$ & $25.5 \%$ \\
\hline \multicolumn{4}{|c|}{$\begin{array}{l}\text { 18. Reading for pleasure has had a positive } \\
\text { effect on my proficiency in English. }\end{array}$} \\
\hline Strongly Disagree & $0 \%$ & $13 \%$ & $6.5 \%$ \\
\hline Disagree & $3 \%$ & $18 \%$ & $10.5 \%$ \\
\hline Not Sure & $15 \%$ & $13 \%$ & $14 \%$ \\
\hline Agree & $58 \%$ & $46 \%$ & $52 \%$ \\
\hline Strongly Agree & $24 \%$ & $10 \%$ & $17 \%$ \\
\hline \multicolumn{4}{|c|}{ 27.Reading novels is a pleasant activity for me. } \\
\hline Strongly Disagree & $0 \%$ & $0 \%$ & $0 \%$ \\
\hline Disagree & $11 \%$ & $15 \%$ & $13 \%$ \\
\hline Not Sure & $8 \%$ & $3 \%$ & $5.5 \%$ \\
\hline Agree & $68 \%$ & $77 \%$ & $72.5 \%$ \\
\hline Strongly Agree & $13 \%$ & $5 \%$ & $9 \%$ \\
\hline
\end{tabular}

Source: Data compiled by author for article

Values are given as means.

PTD, Primary Teacher's Diploma.

TABLE 3: Culturally-held views about extensive reading.

\begin{tabular}{llll}
\hline Culturally-held views & $\begin{array}{l}\text { PTD 1 } \\
(N=\mathbf{4 5})\end{array}$ & $\begin{array}{l}\text { PTD 3 } \\
(\boldsymbol{N}=\mathbf{3 9})\end{array}$ & $\begin{array}{l}\text { Overall } \\
(\boldsymbol{N}=\mathbf{8 4})\end{array}$ \\
\hline $\begin{array}{l}\text { 21. Reading novels and magazines is a } \\
\text { 'woman thing', not for men. }\end{array}$ & & \\
Strongly Disagree & $58 \%$ & $56 \%$ & $57 \%$ \\
Disagree & $31 \%$ & $28 \%$ & $29.5 \%$ \\
Not Sure & $0 \%$ & $3 \%$ & $1.5 \%$ \\
Agree & $7 \%$ & $5 \%$ & $6 \%$ \\
Strongly Agree & $4 \%$ & $8 \%$ & $6 \%$ \\
24. Reading in public places, like in buses & & & \\
and parks, is not 'cool'. & & & \\
Strongly Disagree & $24 \%$ & $21 \%$ & $22.5 \%$ \\
Disagree & $40 \%$ & $49 \%$ & $44.5 \%$ \\
Not Sure & $11 \%$ & $10 \%$ & $10.5 \%$ \\
Agree & $22 \%$ & $15 \%$ & $18.5 \%$ \\
Strongly Agree & $3 \%$ & $5 \%$ & $4 \%$ \\
37. Too much reading can be dangerous as & & & \\
it can lead to mental disturbance. & & & \\
Strongly Disagree & $49 \%$ & $36 \%$ & $42.5 \%$ \\
Disagree & $29 \%$ & $31 \%$ & $30 \%$ \\
Not Sure & $13 \%$ & $21 \%$ & $17 \%$ \\
Agree & $9 \%$ & $8 \%$ & $8.5 \%$ \\
Strongly Agree & $0 \%$ & $4 \%$ & $2 \%$ \\
\hline Source: Da compin & & \\
\hline
\end{tabular}

Source: Data compiled by author for article

Values are given as means.

PTD, Primary Teacher's Diploma.

reading', and the third pertaining to one's 'beliefs about cultural norms concerning reading (conditioned by one's desire to conform to those norms)' (McKenna 2001:139).

The second research instrument used in the study was a criterion-referenced reading comprehension test. It comprised a reading passage and questions based on the passage. Questions requiring literal understanding of the passage, inferential and vocabulary knowledge were to be answered in writing.

The third instrument was a Vocabulary-levels test developed by Laufer and Nation (1995) in which five levels of test difficulty were tested: the 2000, 3000, 5000 and 10000 word levels and the University Word list (UWL).

Academic performance was also measured. Data for this part of the study were gathered from continuous assessment and the examination scores at the end of the academic year. The researcher chose some subjects that would make up the mean score to represent Academic Performance (AP), namely: Academic Communication Skills (ACS), Social Studies, Mathematics, Science and Agriculture. The final grade was made up of $50 \%$ comprising assignments and tests in the individual specialisation subjects and two other subjects: ACS and Education, and 50\% being the final examination score.

\section{Procedure}

The questionnaire was the first to be administered. This was followed by the reading comprehension and vocabulary tests.

\section{Data scoring and analysis}

Eighteen questions in the questionnaire were coded for the variable data on attitudes and perceptions. The raw score obtained from the coding was converted into percentage points for the purposes of statistical analysis. The vocabulary test was marked and the scores were converted to percentage. Academic performance was compiled from the participants' end-of-year results, from key subjects such as English, Mathematics, Science, Agriculture, Academic Communication Skills, Education, Social Studies and siSwati.

\section{Results}

The exploratory question sought to investigate the participants' attitudes toward and perceptions of extensive reading. Based on the questionnaire data, the researcher found that the participants' attitudes toward extensive reading were positive, as depicted in Table 1 below.

It appears that the answer to the exploratory research question, judging from the descriptive statistics above (Table 1), is that the participants were enthusiastic about reading. Below (in Table 2) are some of the questionnaire items and the participants' responses.

The results as shown in Table 2 seem to indicate that the majority of the students (63.5\%) enjoy reading. The students 
TABLE 4: Reading attitudes, Reading ability and Vocabulary knowledge.

\begin{tabular}{|c|c|c|c|c|c|c|}
\hline Class & Reading attitude Mean & Reading attitude SD* & Reading ability Mean & Reading ability SD & Vocabulary Mean & Vocabulary SD \\
\hline PTD $1(N=45)$ & $71.9 \%$ & 9.79 & $54.7 \%$ & 14.06 & $51.3 \%$ & 9.73 \\
\hline PTD $3(N=39)$ & $71.9 \%$ & 8.75 & $50.9 \%$ & 13.00 & $50.6 \%$ & 10.31 \\
\hline Overall $(N=84)$ & $71.9 \%$ & 8.75 & $53.0 \%$ & 13.63 & $51.0 \%$ & 9.95 \\
\hline
\end{tabular}

Source: Date compiled by author for article

Values are given as means.

PTD, Primary Teacher's Diploma; SD means Standard Deviation.

TABLE 5: Word Levels Performance and Quartiles.

\begin{tabular}{|c|c|c|c|c|}
\hline Word level & $\begin{array}{l}\text { PTD } 1 \\
(N=45)\end{array}$ & $\begin{array}{l}\text { PTD } 3 \\
(N=39)\end{array}$ & $\begin{array}{l}\text { Overall } \\
(N=84)\end{array}$ & $\begin{array}{l}\text { Overall quartiles } \\
(N=84)\end{array}$ \\
\hline 2000 & $83.1 \%$ & $83.0 \%$ & $83.1 \%$ & $\begin{array}{l}25 \text { th }=76 \% \\
50 \text { th }=85 \% \\
75 \text { th }=94 \%\end{array}$ \\
\hline 3000 & $62.1 \%$ & $64.7 \%$ & $63.3 \%$ & $\begin{array}{l}25 \text { th }=56 \% \\
50 \text { th }=67 \% \\
75 \text { th }=72 \%\end{array}$ \\
\hline 5000 & $37.2 \%$ & $38.5 \%$ & $37.8 \%$ & $\begin{array}{l}25 \text { th }=25 \% \\
50 \text { th }=38 \% \\
75 \text { th }=50 \%\end{array}$ \\
\hline UWL & $58.9 \%$ & $54.7 \%$ & $56.9 \%$ & $\begin{array}{l}25 \text { th }=50 \% \\
50 \text { th }=56 \% \\
75 \text { th }=67 \%\end{array}$ \\
\hline 10000 & $13.7 \%$ & $11.4 \%$ & $12.6 \%$ & $\begin{array}{l}25 \text { th }=6 \% \\
50 \text { th }=11 \% \\
75 \text { th }=17 \%\end{array}$ \\
\hline
\end{tabular}

Source: Data compiled by author for article

Values are given as means.

PTD, Primary Teacher's Diploma.

felt that reading was a pleasant activity that had made a positive contribution to their proficiency levels in English as an AL. The results also indicated that there are some remnants of culturally-entrenched attitudes to reading that seem to influence the reading patterns of young Swazi students and the population in general.

Responses to the question (\#21, shown in Table 3): 'Reading novels and magazines is a 'woman thing', not for men' indicate that $13.5 \%$ of the participants seem to concur with the statement (including those who responded with Not Sure).

Furthermore, one cannot ignore the fact that the findings indicate that $33 \%$ of the participants responded with 'Not sure' /'Agree' /'Strongly agree' with regard to the statement that it was unacceptable to read in public places, and that about $27 \%$ still felt that too much reading was hazardous to one's mental health. In short, almost a third of the students still seem to harbour rather negative cultural views toward extensive reading. Perhaps this can be linked to negative attitudes culturally-transmitted early in the life of a child.

The next focus is the statistical findings. The second research question was: Is there a relationship between the students' reading attitudes and their AL reading ability? The table below shows the descriptive statistics.

As can be seen, the students' attitudes toward reading seem to be convincingly positive. However, these statistics show a remarkable contrast to the students' reading ability and vocabulary skills. The juxtaposition of the reading performance against the reading attitude scores depicts two distinctly different pictures in that the reading performance displays a mediocre reading ability ranging in the fifties, for a group whose reading attitude levels are relatively high.
A Pearson's Product-Moment Correlation was performed on the two sets of data to test for a statistical relationship. The results indicated that there was no correlation between reading ability and reading attitudes in this study $(r=0.0801, p=0.469)$.

Furthermore, the researcher enquired: Is there a relationship between the students' vocabulary knowledge and their AL reading ability? The descriptive statistics (as shown in Table 4) indicate a clustering of both the reading and vocabulary scores around a Mean in the lower fifties (53\% and 51\% respectively). As in the reading test, the participants' vocabulary skills indicate rather low achievement (Tables 4 and 5).

The performance of the participants in the vocabulary test is interesting in the sense that, on scrutinising the performance at all the word levels, one encounters a remarkable pattern of uniform achievement. The 3000, 5000, University Word List and 10000 word levels appear to be a serious challenge to the participants, with most of them scoring up to half the total score on each word level. Only one student scored $89 \%$ in the UWL. Considering the participants' performance in the 3000 and 5000 word levels, the 10000 word level was, not surprisingly, beyond their capability. None of the participants scored above $50 \%$ in this category, with $89 \%$ of the First Year and $82 \%$ of the Third Year scores clustering between zero and $22 \%$.

The quartiles (shown in Table 5) in the 2000 and 3000 word levels indicated that the 50th and 75th quartiles of the participants appear to have reached mastery (85\%) of the 2000 word level. However, on the whole, the students seem not to have attained mastery of the 3000 word level or any of the other higher levels. The upper $25 \%$ of the class achieved $72 \%$ mastery at the 3000 word level, but even the high performing students had not yet achieved mastery levels $(85 \%)$ at the 3000 word level. None of the quartile groups achieved mastery levels in the University Word List. The results indicated that there was a moderate, albeit highly significant, relationship between the participants' vocabulary knowledge and their reading ability $(r=0.482, p<0.000)$.

Finally, the researcher tested for a relationship between participants' reading ability and their academic performance: Is there a relationship between the students' academic performance and their AL reading ability? Table 6 below shows the descriptive statistics obtained.

As can be seen, the Standard Deviation in the reading ability shows the scores clustering in the mid-fifty per cent mark, as did the academic performance mean. Clearly, the 
TABLE 6: Primary Teacher's Diploma 1 and 3's Academic performance and Reading ability.

\begin{tabular}{|c|c|c|c|c|c|c|}
\hline Variables & $\begin{array}{l}\text { PTD } 1(N=45) \\
\text { Reading Test }\end{array}$ & PTD 1 AP $(N=45)$ & $\begin{array}{l}\text { PTD } 3(N=39) \\
\text { Reading Test }\end{array}$ & PTD 3 AP $(N=39)$ & Overall AP $(N=84)$ & Overall AP quartiles \\
\hline Mean & $54.7 \%$ & $61.1 \%$ & $50.9 \%$ & $56.7 \%$ & $59.1 \%$ & $1 s t=55.3 \%$ \\
\hline Range & $20 \%-80 \%$ & $50 \%-70 \%$ & $20 \%-96 \%$ & $45 \%-68 \%$ & $45 \%-70 \%$ & $2 \mathrm{nd}=60.0 \%$ \\
\hline $\mathrm{SD}^{*}$ & 14.06 & 4.61 & 13.00 & 5.05 & 5.20 & $3 r d=63.0 \%$ \\
\hline
\end{tabular}

Source: Data compiled by author for article

Values are given as means.

PTD, Primary Teacher's Diploma; AP, Academic Performance; SD, Standard Deviation.

statistics indicate homogeneity in the reading and academic performance means. With regard to inferential statistics, the results were remarkable.

The fourth research question was: Is there a relationship between the students' academic performance and their AL reading ability? The null hypothesis was rejected, as a Pearson's ProductMoment correlation coefficient indicated some relationship, albeit a low one, at $r=0.294, p=0.007$ between the subjects' reading ability and their academic performance.

\section{Discussion and recommendations}

The gist and tenor of the study was its provision of empirical evidence that not all is well regarding reading attitudes, academic performance and reading ability in this country. The study findings have raised serious concerns about the reading and vocabulary proficiency of students in the country. The findings suggest that the reading ability of our students is far below the acceptable standards for effective academic pursuits. It was distressing that the participants had not reached mastery of the basic high frequency words (the 2000-3000 word levels) and that they had poor knowledge of common academic words: a grave setback to their reading and academic ability. Reading ability does not necessarily mean that every student will achieve academic success, but being unable to read well usually means that a student will not achieve such success.

Furthermore, the results seem to indicate that the majority of the students have a positive propensity toward reading. Students felt that reading was a pleasant activity that had made a positive contribution to their proficiency levels in English as an additional language. Perhaps the positive attitudes are a step in the right direction towards the intention to read and/or continue reading (Mathewson 2004). The implications of the findings from this study are significant for practitioners in the AL teaching area and for teacher education.

One recommendation is that as language learning and teaching practitioners, we have to make that clarion plea, as stated by Bakka (2000:83): 'Back to books!' Preservice teachers need to get hooked on leisure reading so that they can become real readers and teachers of reading. Greater exposure to academic and leisure texts would undoubtedly increase these students' reading skills as well as their specialised vocabulary knowledge, an achievement that would greatly facilitate the reading and comprehension of academic texts.
Also, a campaign such as South Africa's 'Masifunde Sonke' ('let us all read') would be a good place to start. Such a task might have financial implications; however, there is a need for commitment from all education stakeholders, especially the Ministry of Education, to make a difference in this country's deteriorating reading and academic standards. Clearly, change at the country's educational policy and planning level cannot be overemphasised. Merely paying lip-service to improving the rapidly falling educational standards will only worsen the situation.

McKenna argues that 'if we are to be successful in changing children's attitudes toward reading, we must target the factors that affect those attitudes' (2001:139); one such factor that must be targeted is the child's belief about the outcomes of reading, such as feeling self-confident and stimulated to continue reading. Students should be self-driven to engage in more reading. Mathewson (2004) states that there is a need for the teacher and/or lecturer to get to know the students' motivations, 'values, goals and self-concepts' in relation to reading, through personal discussions, interviews, their writing, their choices of books and through close observation (2004:1455), in order to influence them in a positive manner and help change their attitudes.

Another pertinent recommendation from this study is that, for practical reasons, extensive reading in all genres should cut across the curriculum, involving, ideally, all departments in the institution. In light of this, collateral (additional) reading on content subjects should be a requirement in every subject and/or course. This additional reading should have a mark attached to it and must be reflected in the final grade.

Furthermore, a programme to get teachers started on strategically-planned reading instruction in the schools is recommended. This campaign has to be aimed at empowering teachers in primary schools to start reading and in turn, they would assist Swazi youth to start reading.

In addition, the provision of storybooks in both the home language and English, to pre-school and primary school children throughout the schools situated in low socioeconomic contexts, to be read to the children by their parents or caregivers, would go a long way toward developing and nurturing a culture of reading in the communities, and amongst Swazi children. This would start communities on a reading journey towards the inculcation of a culture of reading and enjoyment, with their own children. 
Furthermore, to complement the above-mentioned recommendation, effort must be made to empower parents and caregivers by engaging them in community literacy programmes so that they, in turn, may assist their children with home-based reading. The community could 'adopt' the children of illiterate parents for this purpose (Lituanas, Jacobs \& Renandya 2001:224). The home environment appears to be very influential in the development of good reading attitudes (Conlon et al. 2006). The professional cadre can help, after some in-service training, to educate and train their communities on how to engage in home-based storybook reading. Roberts' (2008) study indicates that this is a viable option. The success of such efforts could ensure cooperation between home and school literacy programmes.

Moreover, ESL classrooms in this country would benefit from an injection of leisure reading resources. It is true that 'the quality of an education system depends vitally on access to books' (Pretorius \& Mampuru 2007:56). Studies have repeatedly shown that novels are a welcome relief to schools where extensive reading is introduced (Roy-Campbell \& Qorro 1997:134; Izizinga 2000; Elley \& Mangubhai 1983; Elley 1991). However, the ailing economy of Swaziland and misdirected government spending might not accommodate this requirement to provide extensive reading materials for the school and college libraries.

With time and effort, language practitioners may assist in the translation of these negative mainstream beliefs about reading into positive reading behaviour instead of putting up with 'mechanistic literacy', which is superficial literacy that is aimed at simply attaining jobs (Bakka 2000). It is with this outcome in mind that I make the above recommendations for the College, the ESL context in Swaziland and, by extension, the language learning and teaching context in Africa.

\section{Suggestions for further research}

Further research on the complex relationship between reading attitudes and reading ability still needs to be conducted. The current study has only scratched the surface in the local context.

Another area of interest would be that of a longitudinal study, tracking the effectiveness of the students who participated in this study, in the teaching of reading at the primary level, in the schools to which they have been assigned.

Finally, an intervention programme aimed at investigating what extensive reading can achieve with regard to the reading ability, language proficiency and academic performance of College students, could make a difference. This study could involve a long-term intervention project that would require revamping the present College library with leisure reading material in order to get students started on a reading programme. Still, the researcher would do well to heed Green's advice that a programme like this cannot be "a stand-alone" component' in the ESL classroom (2005:308).

\section{Acknowledgements}

The researcher is indebted to the student teachers who participated so willingly in this study and made it possible to learn more about pre-service teachers' reading attitudes, reading ability, vocabulary levels and academic performance in the Swazi context. My gratitude also goes to my supervisor, Prof. E.J. Pretorius, the administrators of the Faculty and the lecturers. Thank you for your role in the completion of this project.

\section{Competing interests}

The author declares that she has no financial or personal relationship(s) which may have inappropriately influenced her in writing this paper.

\section{References}

Bakka, P., 2000, 'Back to Books: Functional Literacy', in K. Parry (ed.), Language and Literacy in Uganda: Towards a sustainable reading culture, pp. 83-87, Fountain Publishers, Kampala.

Camiciottoli, B.C., 2001, 'Extensive reading in English: Habits and attitudes of a group of Italian university EFL students', Journal of Research in Reading 24(2), 135-153. http://dx.doi.org/10.1111/1467-9817.00137

Collier, V.P., 1989, 'How long? A synthesis of research on academic achievement in a second language', TESOL Quarterly 23(3), 509-531. http://dx.doi.org/10.2307/3586923

Conlon, E.G., Zimmer-Gimbeck, M.J., Creed, P.A. \& Tucker, M., 2006, 'Family history, self-perceptions, attitudes and cognitive abilities associated with early adolescent reading skills', Journal of Research in Reading 29(1), 11-32. http://dx.doi.org/ reading skills', Journal of Research in
$10.1111 / \mathrm{j} .1467-9817.2006 .00290 . x$

Corson, D., 1997, 'The learning and use of academic English words', Language Learning 47(4), 352-367. http://dx.doi.org/10.1111/0023-8333.00025

Day, R.R. \& Bamford, J., 1998, Extensive reading in the second language classroom, Cambridge University Press, Cambridge.

Elley, W.B., 1991, 'Acquiring literacy in a second language: The effects of book-based programs', Language Learning 41(3), 375-411. http://dx.doi.org/10.1111/j.1467programs', Language
$1770.1991 . t b 00611 . x$

Elley, W.B. \& Mangubhai, F., 1983, 'The impact of reading on second language learning', Reading Research Quarterly 19(1), 53-67. http://dx.doi.org/10.2307/747337

Feitelson, D., Goldstein, Z., Iraqi, J. \& Share, D., 1993, 'Effects of listening to storybook reading on aspects of literacy acquisition in a diglossic situation', Reading Research Quarterly 28(1), 71-79. http://dx.doi.org/10.2307/747817

Grabe, W., 1991, 'Current development in second language reading research', TESOL Quarterly 25(3), 375-406. http://dx.doi.org/10.2307/3586977

Green, C., 2005, 'Integrating extensive reading in the task-based curriculum', ELT Journal 59(4), 306-311.http://dx.doi.org/10.1093/elt/cci059

Guthrie, J. \& Greaney, V., 1991, 'Literacy acts', in R. Barr, M.L. Kamil, P. Mosenthal \& P.D. Pearson (eds.), Handbook of Reading Research II, pp. 68-96, Longman, New York.

Heath, S.B., 1991, 'The sense of being literate: Historical and cross-cultural features', in R. Barr, M.L. Kamil, P.B. Mosenthal \& P.D. Pearson (eds.), Handbook of Reading Research II, pp. 3-25, Longman, New York.

Izizinga, R., 2000, 'The teaching of reading in Uganda', in K. Parry (ed.), Language and Literacy in Uganda: Towards a sustainable reading culture, pp. 66-70, Fountain Publishers, Kampala.

Just, M.A. \& Carpenter, P.A., 1987, The psychology of reading and language comprehension, Allyn \& Bacon, Boston.

Lao, C.Y. \& Krashen, S., 2000, 'The impact of popular literature study on literacy development in EFL: More evidence for the power of reading', System, 28, 261270. http://dx.doi.org/10.1016/S0346-251X(00)00011-7

Laufer, B. \& Nation, P., 1995, 'Vocabulary size and use: Lexical richness in L2 written production', Applied Linguistics 16(3), 307-322.

Lituanas, P.M., Jacobs, G.M. \& Renandya, W.A., 2001, 'An investigation of extensive reading with remedial students in a Philippines secondary school', International Journal of Educational Research 35, 217-225. http://dx.doi.org/10.1016/S08830355(01)00018-0

Mathewson, G.C., 2004, 'Model of attitude influence upon reading and learning to read', in R.B. Ruddell \& N.J. Unrau (eds.), Theoretical Models and Processes of Reading, pp. 1431-1461, International Reading Association, Newark, DE.

McKenna, M.C., 2001, 'Development of reading attitudes', in L. Verhoeven \& C.E. Snow (eds.), Literacy and Motivation: Reading engagement in individuals and xgroups, pp. 135-158, Lawrence Erlbaum Associates, Mahweh, N.J. 
McKenna, M.C., Kear, D.J. \& Ellsworth, R.A., 1995, 'Children's attitudes toward reading: A national survey', Reading Research Quarterly 30 (4), 934-956.

Min, H-T., 2008, 'EFL vocabulary acquisition and retention: Reading plus vocabulary enhancement activities and narrow reading', Language Learning 58(1), 73-115. http://dx.doi.org/10.1111/j.1467-9922.2007.00435.x

Mokhtari, K. \& Sheorey, R., 1994, 'Reading habits of ESL students at different levels of English proficiency and education', Journal of Research in Reading 17(1), 46-61. http://dx.doi.org/10.1111/j.1467-9817.1994.tb00051.x

Pretorius, E.J., 2002, 'Reading ability and academic performance in South Africa: Are we fiddling while Rome is burning?', Language Matters 33, 169-196. http:// dx.doi.org/10.1080/10228190208566183

Pretorius, E.J., 2005, 'What do students do when they read to learn? Lessons from five case studies', South African Journal of Higher Education 19(4), 790-812.

Pretorius, E.J. \& Bohlmann, C.A., 2003, 'A reading intervention programme for mathematics students', South African Journal of Higher Education 17(2), 226-236.
Pretorius, E.J. \& Mampuru, D.M., 2007, 'Playing football without a ball: Language, reading and academic performance in a high poverty school', Journal of Research reading and academic performance in a high poverty school', Journal of Research
in Reading 30(1), 38-58. http://dx.doi.org/10.1111/j.1467-9817.2006.00333.x

Roberts, T.A., 2008, 'Home storybook reading in primary or second language with preschool children: Evidence of equal effectiveness for second-language vocabulary acquisition', Reading Research Quarterly 43(2), 103-130. http://dx.doi.org/10.1598/ RRQ.43.2.1

Roy-Campbell, Z.M. \& Qorro, M., 1997, Language Crisis in Tanzania: The myth of English versus education, Mkuki na Nyota, Dar es Salaam.

Smith, C.M., 1990, 'A longitudinal investigation of reading attitude development from childhood to adulthood', Journal of Educational Research 83(4), 215-219.

Stanovich, K.E., 1991, 'Word recognition: Changing perspectives', in R. Barr, M.L. Kamil, P.B. Mosenthal \& P.D. Pearson (eds.), Handbook of Reading Research II, pp. 418-453, Longman, New York.

Walberg, H.J. \& Tsai, S-L., 1995, 'Correlates of reading achievement and attitude: A national assessment study', Journal of Educational Research 78(5), 159-167. 